\title{
La tumba de Antígona de María Zambrano. A propósito de la figura de Ana
}

\author{
Marta GonZÁLEZ GonZÁLEZ \\ Universidad de Málaga \\ martagzlez@uma.es
}

RESUMEN: Aproximación a la obra de María Zambrano, La tumba de Antígona, atendiendo a las singularidades de esta recreación mítica y, sobre todo, al personaje de la nodriza, Ana, que no aparece en la pieza de Sófocles y que tiene en la obra de Zambrano una especial importancia.

\section{Antigona's Grave by Maria Zambrano. An Approach to Ana's Character}

ABSTRACT: This article is an approach to María Zambrano's play Antigona's Grave, paying attention to the peculiarities of this mythical recreation. In a special way, we analyze the character of the nurse, Ana, which is not found in Sophocles and yet is very important in Zambrano's recreation. 



\title{
La tumba de Antígona de María Zambrano. A propósito de la figura de Ana ${ }^{1}$
}

\author{
Marta GonZÁLEZ GonZÁlEZ
}

Antígona, en verdad, no se suicidó en su tumba, según Sófocles, incurriendo en un inevitable error, nos cuenta.

María Zambrano (Málaga, 1904-Madrid, 1991) pone fin a La tumba de Antígona en 1964 y la publica en México en 1967. Se trata, en una autora que defendió la ausencia de separación entre filosofía y poesía, de su obra más poética. En las breves páginas que siguen vamos a centrarnos en dos únicos puntos, muy concretos: la singularidad de la recreación de Zambrano y la simbología del personaje de la nodriza Ana, que no aparece en Sófocles y al que la autora malagueña concede significativa importancia.

Algunas consideraciones previas sobre el tipo de recreación mítica por la que opta Zambrano

Las palabras de María Zambrano, "Antígona, en verdad, no se suicidó en su tumba, según Sófocles, incurriendo en un inevitable error, nos cuenta", podrían leerse como aquellas de Estesícoro sobre Helena: "No es cierto ese relato, ni embarcaste en las naves de firme cubierta ni llegaste a la fortaleza de Troya"; es decir, se trata de variantes del mito (simplemente, Antígona dispondría de un poco más de tiempo ${ }^{2}$ ) o, en caso de que consideremos el suicidio casi inmediato de Antígona como el hecho fundamental en el relato, de una revisión absoluta. Puede entenderse este texto como eminentemente poético, y no cabe leerlo siguiendo estrictamente las interpretaciones

${ }^{1}$ Este trabajo se adscribe al Grupo de investigación 930136 de la Universidad Complutense: "Historiografía de la literatura grecolatina en el siglo XIX español".

${ }^{2}$ Esta prolongación de la historia de Antígona es resaltada por Lezama Lima en una carta a Zambrano (28 de junio de 1968, reproducida en Cuadernos del Norte, 8): "Por eso, sus páginas sobre Antígona nos tocan en lo más hondo y verídico de nosotros; el cumplimiento de un destino más allá de la muerte, como el fatum, es la mejor ayuda del hombre". 
académicas (por otra parte innumerables) que el mito sofocleo de Antígona continúa provocando. ${ }^{3}$ ¿Qué podría haber movido a María Zambrano a escribir esta prolongación del mito de Antígona? Las claves nos las proporciona la propia autora en el prólogo, en las primeras líneas:

Sin ella [sc. Antígona] el proceso trágico de la familia y de la ciudad no hubiera podido proseguir ni, menos aún, arrojar su sentido. Pues que el conflicto trágico no alcanzaría a serlo, a ingresar en la categoría de la tragedia, si consistiera solamente en una destrucción; si de la destrucción no se desprendiera algo que la sobrepasa, que la rescata. Y de no suceder así, la tragedia sería nada más que el relato de una catástrofe o de una serie de ellas, en el cual, a lo más, se ejemplifica el hundimiento de un aspecto de la condición humana o de toda ella. ${ }^{4}$

Parece claro, por este pasaje, y otros como el que recogeremos a continuación, que María Zambrano tiene siempre en mente, cuando reflexiona sobre la tragedia de Antígona, la de Orestes. En la Orestíada, tal como la conocemos por Esquilo, existe un final de las tragedias familiares, un punto de inflexión que Zambrano parece echar en falta en la saga de los Labdácidas. Esa visión defectiva del mito de Antígona respecto a la figura de Orestes reaparece cuando la autora habla de la ausencia de apoyo divino para la joven:

en la tragedia Antígona de Sófocles, los dioses no intervienen. Ningún oráculo divino le ha señalado a esta muchacha su destino. Apolo nada le dijo y quizá por ello, ni él ni su hermana Atenea se preocuparon de su suerte. ${ }^{5}$

${ }^{3}$ Si no le concedemos a María Zambrano esa licencia poética, sólo nos quedaría criticar su falta de comprensión ante el ambiguo juego de razones que asisten a Antígona y a Creonte en la obra de Sófocles. Así, Pino Campos (2005, p. 249) cuestiona seriamente la afirmación que abre la obra de Zambrano: "Lo que en todo caso se puede calificar de error literario, filosófico e histórico es la irrupción radical y desmesurada de María Zambrano en la obra de Sófocles", para a continuación argumentar a favor de la versión sofoclea: "Sin duda, en la obra de Sófocles Antígona tenía su razón para actuar como lo hizo, una razón familiar y personal y, si se prefiere, una razón divina, pero Creonte no sólo tenía su justificación para dictar aquel decreto prohibitivo de tan funestas consecuencias, sino que le asistían todas las razones jurídicas, religiosas y políticas vigentes en aquella época histórica (s. V a. C.)" (ib., p. 250). Por supuesto, en las conclusiones, el autor aboga por entender las dos versiones, la de Sófocles y la de Zambrano, en sus respectivos contextos. La bibliografía sobre el enfrentamiento y las "razones" de Antígona y de Creonte es extensísima; entre las aportaciones recientes, vid. Iriarte, 2004.

${ }^{4}$ M. Zambrano, 1989, p. 17. Las citas están tomadas de esta edición.

${ }^{5}$ Ib., p. 21. 
Y, de forma más explícita, en otro pasaje, esta vez de El hombre y lo divino:

[Atenea] Divinidad que profetiza el ser, que figura la unidad política y social de una ciudad es, sin embargo, una muchacha, cuya severidad proviene del esfuerzo que se ve obligada a realizar. Una muchacha cargada con las armas del padre, contraída en un esfuerzo que linda con el dolor. Su imagen llamada "melancólica" del bajorrelieve del Museo de Atenas, la muestra sorprendida en una actitud que denuncia su secreto fondo. Sin escudo ni collar descansa apoyada la frente sobre la lanza inclinada [...]. Incólume e indecisa, ha de ser inexorable y cumplir esa fatiga del juicio, como en su intervención cerca de Orestes, absolviéndole de su crimen por mantener la ley del padre. [...] La frialdad de la aurora la baña; luz pura sin vibración de calor, virgen, dejará sin protección a las heroínas de la conciencia, a Antígona, tan de su estirpe, bajar al sepulcro. ${ }^{6}$

Cerrando el argumento, en los párrafos finales del prólogo a su particular recreación, María Zambrano vuelve a la historia de Orestes y a la intervención de Atenea:

Y si Orestes hubiera quedado entregado a las furias de venganza inacabable, todo habría quedado ahí, en la venganza que no cesa y que por lo mismo, como toda venganza que no cesa, no alcanza a ser historia. ${ }^{7}$

De manera que ese tiempo que, en opinión de Zambrano, se le debe a la heroína y que le permitirá cerrar las heridas familiares, es el que la autora le concede en La tumba de Antígona. En el transcurso de esta especie de epílogo a la tragedia griega, la hija de Edipo recibe la visita de varios personajes, además de pronunciar dos monólogos dirigidos: uno a Ismene y otro a Yocasta, a quienes considera "sueño" y "sombra", respectivamente, y que no toman la palabra. En primer lugar, en "Sueño de la hermana", recibe la visita de Ismene, personaje que no aparece, según acabamos de señalar, como interlocutor directo; después, la de dos figuras con las que sí dialoga, su padre, Edipo, y Ana, la nodriza, personaje inventado por Zambrano y cargado de fuerte simbolismo, como veremos; a continuación, en "La sombra de la madre", aparece otra figura crucial, Yocasta, pero, de nuevo, en forma de presencia intangible y no de personaje; entra

\footnotetext{
${ }^{6}$ M. Zambrano, 1999, pp. 169-170.

${ }^{7}$ Ib., 1989, p. 29.
} 
Antígona, finalmente, en diálogo con la Harpía, con los dos hermanos, Eteocles y Polinices, con Hemón y, para terminar, con Creonte.

\section{Las dos obras frente a frente. Tradición e innovación. ${ }^{8}$}

La soledad de Antígona y la figura de Ana, la nodriza

De forma natural, al continuar la historia de Antígona desde unos momentos antes de que Sófocles la hubiera abandonado, escuchamos la voz de la heroína (voz que, de manera quizá un tanto injusta hacia Sófocles, es vista por algunos autores como innovación absoluta ${ }^{9}$ ), sola y encerrada en su tumba de piedra. Esa soledad de Antígona, que parece obsesionar a María Zambrano, es explotada sin atender, de nuevo, a las razones que, en un contexto exclusivamente sofocleo, podrían explicarla. La soledad que, en clave trágica, sería antes que nada un tópico que contribuye a la caracterización del héroe,$^{10}$ es considerada por Zambrano, en cambio, como una de las particularidades de la hija de Edipo y en términos casi exclusivos de abandono de los dioses (especialmente Atenea y Apolo, como ya hemos visto), razón por la cual las primeras palabras de su Antígona son las siguientes: "Vedme aquí dioses, aquí estoy, hermano". Por otra parte, la frase "aquí estoy hermano" enlazaría de nuevo su texto con el de Sófocles, que había puesto en labios de la joven la seguridad de un pronto reencuentro con los suyos. ${ }^{11}$

Hay innovación en los personajes del drama y parece especialmente significativa la introducción de la figura de la nodriza Ana. Se han propuesto, hasta donde sé, dos interpretaciones para este personaje. Por un lado, uno de los autores que más ha estudiado a María Zambrano, L. M. Pino Campos, entiende que se trata de un personaje inspirado posiblemente en la madre de la Virgen María, que fue amamantada por Santa

${ }^{8}$ Como ya señalábamos más arriba, vamos a limitarnos, en la práctica, a un único punto, el de la figura de Ana. Un estudio de conjunto sobre las innovaciones que presenta esta obra de Zambrano puede verse en Picklesimer, 1998.

${ }^{9}$ Castillo, 1983, pp. 10-11: “Alguien nos habla, por primera vez, en favor de la doncella, alguien que no se ha limitado a escuchar sus quejas, le ha tendido una mano, y aún más, ha puesto toda la claridad de su pensamiento en prestarle su razón a Antígona”, o Balcells, 2004, p. 343: "hasta entonces [sc., la publicación de la obra de Zambrano] nunca se había dotado de voz propia a la malhadada muchacha”.

${ }^{10}$ Vid., de nuevo, Iriarte, 2004, p. 51, con bibliografía.

${ }^{11}$ Ant., 867-868, 892 y ss. 
Ana, lo mismo que esta Antígona zambraniana lo fue por dicha ama. ${ }^{12}$ Por otra parte, también se ha sugerido una alusión a la Ana virgiliana, hermana de Dido. ${ }^{13}$

Se trata de dos interpretaciones no forzosamente excluyentes y que quizá puedan aunarse un tanto atendiendo, por un lado, a la importancia que en la obra de Zambrano tienen las figuras de Ismene, muy especialmente,

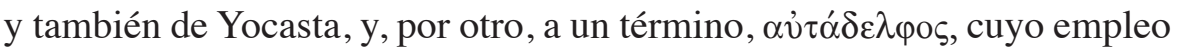
por parte de la Antígona, esta vez la sofoclea, es muy significativo. ${ }^{14}$

La figura de Ismene es clave en la recreación de Zambrano. Aparece de una manera tan intensa que incluso sería más apropiado para ella el califi-

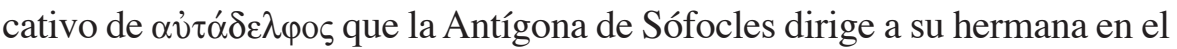
primer verso de la tragedia. ${ }^{15}$ Antígona, en Zambrano, recuerda a su familia, "padre, madre, hermana, hermano y hermano" (p. 42), y es la hermana, en ese lugar privilegiado, la que ocupa la primera escena del relato. En ese "Sueño de la hermana" alude a cómo Ismene quiso morir con ella:

Pero yo no te dejé. Y él, el hombre ese del poder, el que mandaba - ¿Todavía está ahí, mandando?-. El que manda para condenar pareció obedecer a mi voluntad - pues que en algo me tenía que obedecer él a mí-. Y no te condenó a muerte, quiero decir: te condenó a vivir sin mí —él condena siempre - y con la angustia de haber perdido el secreto, como un anillo que se rompe y ya no le sirve a nadie. ${ }^{16}$

12 Pino Campos, 2004, p. 270.

${ }^{13}$ Picklesimer, 1998, p. 366: "la Ana de Antígona nos recuerda a la Ana de Dido en la Eneida, la hermana que sólo parece existir como un alter ego de Dido, como su subconsciente".

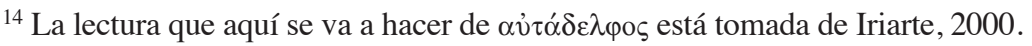

${ }^{15} \mathrm{Y}$ esto a pesar de las apariencias, y a pesar de que, como se ha señalado, Ismene no figura como interlocutora en la obra de Zambrano. Vid. Balcells, 2004, pp. 345-346: "Ismene, hermana de Antígona, no participa como su interlocutora en el texto zambraniano, pero sí se cruza por el pensamiento de la enterrada. Sófocles otorgó a este personaje un papel más relevante que el que se le da en La tumba de Antígona".

${ }^{16}$ M. Zambrano, 1989, p. 46. No sé hasta qué punto María Zambrano, que había leído a Kierkegaard, alude aquí a su estudio sobre la heroína griega. Kierkegaard habla del secreto que pesa sobre Antígona (p. 62 de la versión castellana): "El ser humano que oculta un secreto en su seno, está, por decirlo así, ennoblecido; y nada hay, indudablemente, que ennoblezca más que un secreto. Su vida adquiere un significado que sólo existe para él mismo, y esto le libera de todo miramiento en cuanto al mundo externo; al bastarse a sí misma, descansa serenamente sobre su secreto, aunque éste sea el más infortunado de los secretos. 
La intimidad entre las hermanas reaparece de nuevo al final del diálogo de Antígona con sus dos hermanos varones. Eteocles pregunta por ella, por qué no está en este encuentro entre hermanos. Y Antígona responde:

Ella es la única de nosotros que tendrá su propia vida. Y, por lo demás, ella está siempre conmigo; irá conmigo donde yo vaya. ${ }^{17}$

En fin, en el diálogo con Creonte, reaparece la hermana en uno de los pasajes más emotivos de la pieza:

CREONTE: ¿Y qué diré a tu hermana que te espera?

AnTígona: Dile, si te acuerdas bien, dile - no cambies mis palabras - que viva por mí, que viva lo que a mí me fue negado; que sea esposa, madre, amor. Que envejezca dulcemente, que muera cuando le llegue la hora. Que me sienta llegar con la violeta inmortal, en cada mes de abril, cuando las dos nacimos. ${ }^{18}$

CREONTE: ¿Y cómo yo voy a poder decirle todo eso? Eso son cosas tuyas.

ANTíGOnA: Y cómo voy a decir cosas no mías y a mi hermana, a lo único que de mí dejo en esa vida. Pero no es necesario que se lo digas. Yo sé que será así. ${ }^{19}$

De modo que, aunque no sea un "personaje" al modo de los otros (Edipo, Eteocles, Polinices, Hemón o Creonte), Ismene es una presencia real en la obra, como lo es también el otro "no personaje", la madre, Yocasta.

Como acabamos de mencionar, Yocasta no interviene en la obra para dialogar con Antígona. Pero su figura aparece en dos lugares importantes: en el diálogo que la heroína mantiene con su padre y, después de la intervención de la nodriza, en el capítulo "La sombra de la madre". En el diálogo con Edipo, que la nombra sólo como "Ella", es Antígona quien la reivindica como madre también suya:

Así es nuestra Antígona”. Si realmente aquí hubiera un eco de Kierkegaard, Zambrano estaría de nuevo utilizando este motivo para reforzar la intimidad entre las hermanas ya que, en su versión, de lo que se habla es de un secreto compartido por las dos. Se había hecho alusión a él en el "Sueño de la hermana" ("nosotras tenemos nuestro secreto, lo tuvimos siempre", p. 45), y ahora se retoma para afirmar que Ismene lo ha perdido al perderla a ella.

${ }^{17}$ M. Zambrano, 1989, p. 80.

${ }^{18}$ Aunque no es propósito de este trabajo hacer crítica biográfica, sólo como curiosidad señalamos que María Zambrano había nacido un 22 de abril de 1904, y su hermana Araceli (a quien va dedicado el libro) el 21 de abril de 1911.

${ }^{19}$ M. Zambrano, op. cit., p. 87. 
Tengo también que escucharte esto, que me hables de ella, de ella. Ella, ¿no lo sabes? era mi madre y lo será siempre. ¿O es que me quieres dejar sola? Sola para que sólo sea tu hija. Porque eso sí. Siempre fue así. Me tratabas como si solamente fuera hija tuya. Sola, sí, me querías. ${ }^{20}$

La Antígona de Zambrano, de quien Edipo dice que ha nacido de su solo pensamiento, ${ }^{21}$ reivindica la figura de su madre. Yocasta es su madre y lo será siempre, ese mismo siempre que leíamos más arriba, acerca de Ismene, "ella está siempre conmigo".

Al final del episodio que Zambrano titula "La sombra de la madre", Antígona dice sentirse purificada por esa sombra que la ha atravesado. Da un nuevo paso hacia ese "amanecer de la conciencia" que es, al fin y al cabo, la razón de ser de este tiempo de más que Zambrano le ha regalado.

La madre, pues, y la hermana, dos personajes clave en la recreación del mito que estamos analizando, pese a ser los dos únicos que, se podría decir, aparecen y no aparecen, son y no son, en sentido estricto, personajes como los demás. Veamos si el propio Sófocles, de quien aparentemente tanto se aparta María Zambrano, puede venir en nuestra ayuda para entender la importancia de ambos personajes y su posible simbiosis en la figura de la nodriza.

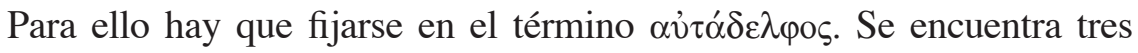
veces en el texto griego y podría servirnos para "ensanchar" esa idea de fraternidad a la que todos los autores (tanto los poetas como sus intérpretes) se han referido desde que el mito de Antígona nos acompaña. ${ }^{22}$ María Zambrano recoge este vocablo griego en el prólogo (paradójicamente, para nuestro argumento, al referirse a la fraternidad entre Antígona y su hermano

${ }^{20}$ M. Zambrano, 1959, p. 50.

${ }^{21}$ Nuevo eco de la idea, recurrente en Zambrano, de una Antígona "tan de la estirpe de Atenea".

${ }^{22}$ Muy especialmente Steiner, 1987, p. 26, con su retórica sin fisuras, tan impermeable a primera vista: "Hay sólo una relación humana en la que el yo puede negar su soledad sin apartarse de su auténtico modo de ser. Hay sólo un modo de encuentro en el que el yo halla al yo en otra persona, en que yo y no yo (las polaridades kantianas, fichteanas, hegelianas) se hacen una sola cosa. Es una relación entre hombre y mujer, como seguramente debe serlo para salvar las brechas primarias del ser. Pero hay una relación entre hombre y mujer que resuelve la paradoja de la alienación inherente a toda sexualidad (una paradoja que el incesto no haría sino afianzar). Es la relación de hermano y hermana, de hermana y hermano". El énfasis es, por supuesto, del autor. 
Polinices) interpretándolo como "la misma hermana, la hermana absoluta". Aunque, paso a paso, de manera imperceptible pero firme, hemos visto cómo iba abriendo "claros" que acogían la relación Antígona-Ismene en esa "fraternidad".

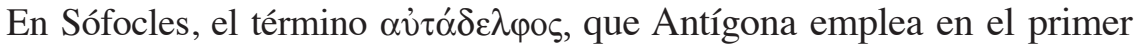
verso de la tragedia al interpelar a Ismene, alude a la fraternidad insistiendo

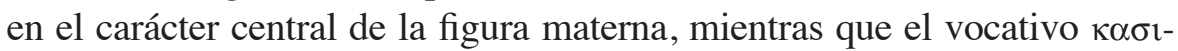
$\gamma v \eta \dot{\tau} \eta$, con el que la hermana le responde, señala el valor social y patriarcal de esta relación. Todos los ejemplos que la obra de Sófocles ofrece del primer término están directamente asociados a Antígona:

Le célèbre koinon autadelphon kara qu'Antigone adresse à Ismème réunit une série de termes qui soulignent l'extrême ressemblance entre ces soeurs nées de parents qui sont, à leur tour, mère et fils. Or, parmi ces termes, se distingue, par la redondance qu'il implique, le composé autadelphos, terme désignant la «fraternité» tout en renforçant la signification d'adelphos — du «même sein»- et qui apparaît strictement associé à Antigone dans tous les emplois que la pièce en fait. ${ }^{23}$

De manera que se subraya la estrecha relación entre ambas hermanas, pero no de una manera cualquiera, sino enfatizando el papel de la madre.

Por otra parte, el propio nombre de la nodriza, Ana, trae de manera inevitable a la memoria el nombre de otra hermana, el de la Dido de Virgilio. En el libro IV de la Eneida, una Dido enloquecida ante la partida de Eneas se dirige a su hermana (unanimam sororem, leemos en el verso 8) de la siguiente manera: Anna soror, quae me suspensam insomnia terrent! (v. 9). Le cuenta sus tormentos y la hermana le responde de la siguiente manera:

Anna refert: o luce magis dilecta sorori, solane perpetua maerens carpere iuuenta nec dulcis natos Veneris nec praemia noris? $?^{24}$

También son importantes las palabras finales de Ana, cuando descubre el suicidio de Dido:

${ }^{23}$ Iriarte, 2000, p. 61.

${ }^{24}$ Aen., 31-33: “Ana le respondió: 'Hermana mía, a quien quiere tu hermana más que a la misma luz, ¿vas a dejar que entristecida, sola, se vaya consumiendo toda tu juventud sin gozar la dulzura de los hijos ni los dones de Venus?'”, traducción de Javier EchaveSustaeta. 
hoc illud, germana, fuit? me fraude petebas?

hoc rogus iste mihi, hoc ignes araeque parabant?

quid primum deserta querar? comitemne sororem spreuisti moriens? $?^{25}$

Sería quizá mucho decir que Dido y Ana remiten, por levemente que fuera, a Antígona e Ismene. ${ }^{26}$ Serían demasiadas las distancias que habría que salvar. Pero a veces, desde un punto de vista meramente literario, poético, los ecos entre obras y autores nos ofrecen este tipo de saltos. La nodriza de María Zambrano, una madre con nombre de hermana puede, sin duda, despertar en el lector todos los recuerdos literarios que hemos mencionado.

Es un viaje complicado el que proponemos, desde Sófocles a María Zambrano, pasando por Virgilio (del que suponemos también que, previamente, ha viajado hasta Sófocles), y sirviéndonos incluso de una obra tan alejada de todas estas como es el conocido relato de Marguerite Yourcenar: ¿qué parecido hay, después de todo, entre Dido-Ana y la pareja Ana-Miguel en Anna, soror? A cualquier lector actual, el título de Anna, soror le hace pensar en las desesperadas palabras de Dido dirigidas a su hermana en la Eneida, aunque, de hecho, con lo que se encuentra es con los amores incestuosos de una pareja de hermanos (hermano y hermana) que nada tienen que ver con la epopeya virgiliana. Y así, contra toda la lógica temporal que marca los estudios sobre influencias, este breve relato de la autora francesa puede servir de nexo entre Antígona-Polinices y Dido-Ana.

La Ana de María Zambrano es, como Ismene, como Yocasta, alguien muy cercano a Antígona ("Estuve siempre junto a ti", p. 56, de nuevo siempre), y su presencia en el lugar central de La tumba de Antígona podría, pues, hacer las veces de ambas, de madre y de hermana, materializar la voz de dos figuras que, pese a la importancia que hemos visto que tienen, carecen de entidad física en la obra.

${ }^{25}$ Aen., 675-678: “¡Esto te proponías, hermana! ¡Pretendías engañarme! ¡Esto me reservaban este fuego, esta pira, estos altares! ¿Por dónde empiezo a lamentarme de tu abandono? ¿Has desdeñado que tu hermana te hiciese compañía al morir?”. Énfasis nuestro.

${ }^{26}$ Hay, sin embargo, alguna otra propuesta interpretativa en la que se sugieren paralelismos entre las figuras de Antígona e Ismene y las de Dido y Ana, aunque sobre aspectos diferentes a los que aquí estamos tratando. Vid. Dyck, 1983, especialmente p. 241. 


\section{BIBLIOGRAFÍA}

BALCELls, José María, "María Zambrano y su recreación filosófica de Antígona", en AA. VV., María Zambrano: raíces de la cultura española, Madrid, 2004, pp. 341358.

CAstillo, Julia, "La Antígona de María Zambrano", Litoral, 121-123, 1983, pp. 9-15.

DYcK, Andrew, "Sychaeus", Phoenix, 37.3, 1983, pp. 239-244.

IRIARTE, Ana, "Ismène, Chrysothémis et leurs soeurs", Kernos, Suppl. 10, 2000, pp. 57-66.

_, "Antigone autonomos", en L. Couloubaritsis y J.-F. Ost (eds.), Antigone et la résistance civile, Bruselas, Éditions Ousia (Collection "Mythes et Religions"), 2004, pp. 41-55.

KIERKEGAARD, Søren, Antígona, versión española de Juan Gil-Albert, Sevilla, Editorial Renacimiento, 2003.

Picklesimer, María Luisa, “Antígona: de Sófocles a María Zambrano", Florentia iliberritana, Revista de Estudios de Antigüedad Clásica, 9, 1998, pp. 347-376.

Pino Campos, Luis Miguel, "María Zambrano, discípula de Ortega y Gasset", en AA. vV., María Zambrano. Raíces de la cultura española, Madrid, 2004, pp. 187-308.

_, "La condena de Antígona y el exilio de María Zambrano: apuntes en torno a la historia sacrificial", Revista de Filología de la Universidad de la Laguna, 23, 2005, pp. 247-264.

STEINER, George, Antígonas, Barcelona, Gedisa, 1987.

Zambrano, María, El hombre y lo divino, Madrid, Edición de El Círculo de Lectores (Colección Ensayo Contemporáneo), 1999.

_, La tumba de Antígona, Madrid, Mondadori, 1989. 